\title{
APPROACHES FOR THE ASSESSMENT OF THE RESIDUAL STRENGTH OF CONCRETE EXPOSED TO FIRE
}

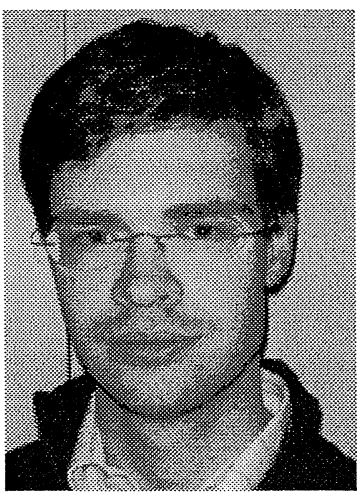

Emmanuel

Annerel $^{*}$

Research assistant

Ghent University,

Belgium

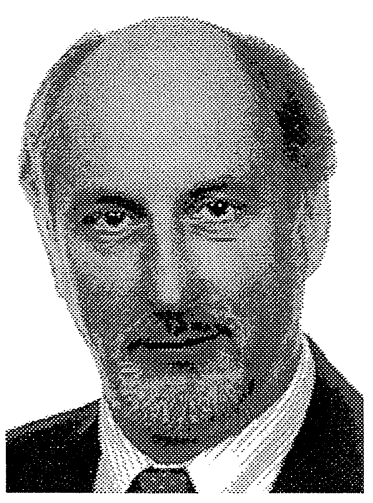

Luc Taerwe

Professor

Ghent University, Belgium

Keywords: colorimetry, cracks, strength assessment, Rebound Index, microscopy

\begin{abstract}
This paper deals with some fundamental aspects of a scientific and systematic methodology to assess the damage and to estimate the residual strength of concrete members after fire exposure. Methods based on the change in colour and porosity, as well as surface hardness, water immersion and microscopy are outlined.
\end{abstract}

\section{INTRODUCTION}

Generally, concrete structures have a very good fire resistance. Although damage to the concrete gradually appears with increasing temperature, concrete structures in most cases don't collapse during a fire. After fire, it is of economical interest to reuse the structure after appropriate repair based on a reliable assessment of the residual strength. The effect of fire on

\footnotetext{
* Corresponding author - Magnel Laboratory for Concrete Research, Departament of Structural Engineering. Faculty of Engineering. Ghent University - Technologiepark Zwijnaarde 904 B-9052 Ghent. Belgium. Telef.: +32 92645519 - Fax: +32 926458 45. e-mail: emmanuel.annerel@UGent.be
} 
the strength of traditional concrete has been studied for a long time and typical models can be found in codes [1]. However, the behaviour of self-compacting concrete (SCC) under fire load is not yet widely investigated. One of the main topics in fire research today is the assessment of the residual strength after fire exposure. Concrete that is heated to high temperatures develops cracks and changes in colour from red $\left(300-600^{\circ} \mathrm{C}\right)$ to whitish grey $\left(600-900^{\circ} \mathrm{C}\right)$ and buff $(900$ $1000^{\circ} \mathrm{C}$ ). In [2] and [3], it is shown that both alterations can be linked to the residual strength, because they are all function of the temperature. Assessing the temperature based on the alterations should therefore give enough information for the estimation of the residual strength of the heated structure. In [4] and [5] the effect of the test conditions on the strength degradation is discussed, namely the heating rate, the time spent at target temperature and the cooling method. [5] and [6] present a certain degree of recovery of the concrete strength depending on the type of storage after fire. All these parameters are important for a good analysis, because they determine the value of the actual residual strength which is necessary for structural calculations.

\section{RESIDUAL STRENGTH}

\subsection{Compressive strength reduction}

Table 1 summarises the mix design of the self-compacting concrete (SCC) and the traditional vibrated concretes with siliceous aggregates (TC) and calcareous aggregates (TCk) used in the test program. One hundred fifty millimetre cubes were cured for 4 weeks in an air-conditioned room at a RH $>90 \%$ and a temperature of $20 \pm 1{ }^{\circ} \mathrm{C}$, after which they were stored at $60 \% \mathrm{RH}$ and $20 \pm 1^{\circ} \mathrm{C}$ for drying until the testing age of 17 weeks. During the three weeks before testing, the SCC cubes were dried at $105^{\circ} \mathrm{C}$ to avoid explosive spalling. Two cubes were heated for each of the examined temperature levels (till $800^{\circ} \mathrm{C}$ ), occurring at a heating rate of $3.5^{\circ} \mathrm{C} / \mathrm{min}$. The target temperature was kept constant for 750 minutes, after which the cubes were cooled in ambient air after removal from the furnace.

Table 1- Concrete mix design

\begin{tabular}{|l|c|c|c|}
\hline & $\begin{array}{c}\text { SCC- } \\
\text { siliceous }\end{array}$ & $\begin{array}{c}\text { TC }- \\
\text { siliceous }\end{array}$ & $\begin{array}{c}\text { TCk - } \\
\text { calcareous }\end{array}$ \\
\hline sand $\left[\mathrm{kg} / \mathrm{m}^{3}\right]$ & 782 & 640 & 663 \\
\hline gravel $2-8 \mathrm{~mm}\left[\mathrm{~kg} / \mathrm{m}^{3}\right]$ & 300 & 525 & - \\
\hline gravel $8-16 \mathrm{~mm}\left[\mathrm{~kg} / \mathrm{m}^{3}\right]$ & 340 & 700 & - \\
\hline limestone $2 / 6$ & - & - & 450 \\
\hline limestone $6 / 20$ & - & - & 759 \\
\hline portland cement I $52.5\left[\mathrm{~kg} / \mathrm{m}^{3}\right]$ & 400 & 350 & 350 \\
\hline water $\left[\mathrm{kg} / \mathrm{m}^{3}\right]$ & 192 & 165 & 165 \\
\hline limestone powder $\left[\mathrm{kg} / \mathrm{m}^{3}\right]$ & 300 & - & - \\
\hline superplasticizer $\left[1 / \mathrm{m}^{3}\right]$ & 2.90 & - & - \\
\hline W/C $[-]$ & 0.48 & 0.47 & 0.47 \\
\hline compressive strength $28 \mathrm{~d}\left[\mathrm{~N} / \mathrm{mm}^{2}\right]$ & 65.9 & 56.5 & 60.3 \\
\hline
\end{tabular}


Figure 1 shows the increase of temperature in the centre of the $\mathrm{SCC}$ cubes for heating to $350^{\circ} \mathrm{C}$ and $550^{\circ} \mathrm{C}$. The drop at the start of the curves is caused by the initial temperature of the furnace of $20^{\circ} \mathrm{C}$, while the $\mathrm{SCC}$ cubes were preheated to $105^{\circ} \mathrm{C}$. Figure 2 illustrates the mean residual compressive strength immediately after cooling down to ambient temperature, in this graph $\theta_{0}$ is taken $20^{\circ} \mathrm{C}$ for $\mathrm{TC}$ and $105^{\circ} \mathrm{C}$ for SCC. Notice that both curves are situated around the Eurocode curves for normal siliceous concrete [1].
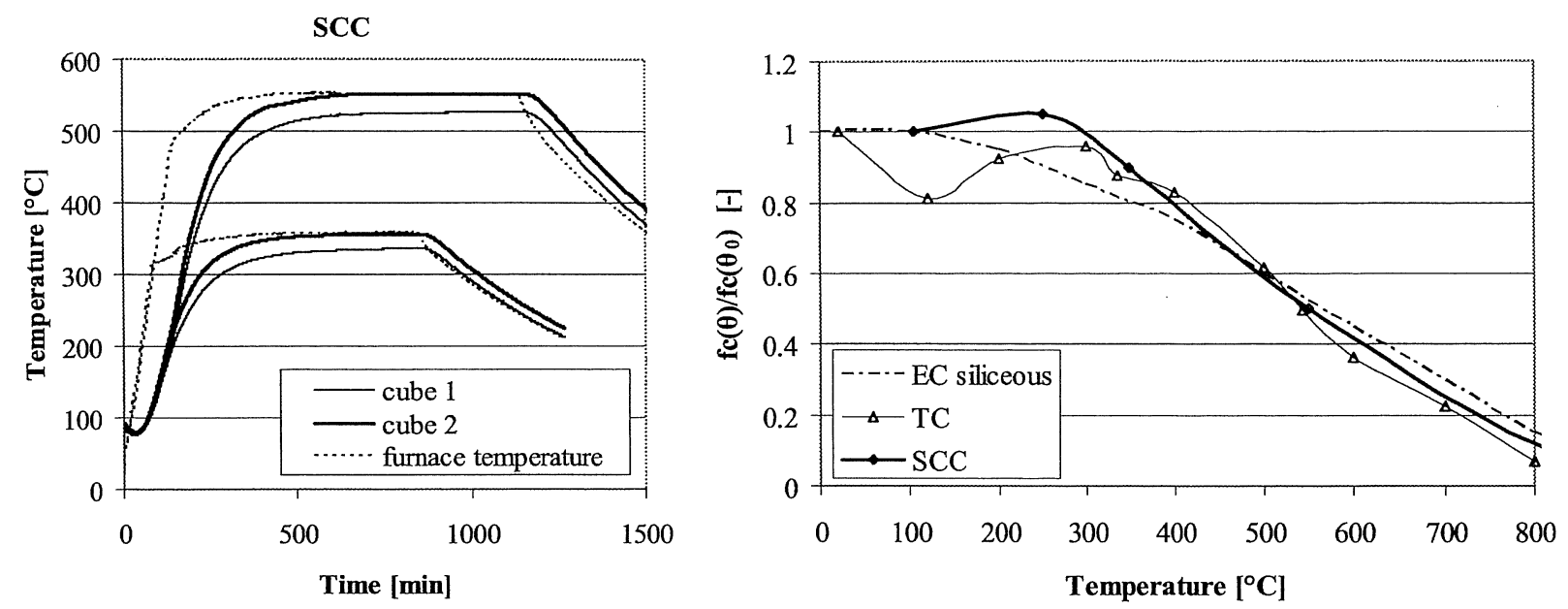

Figure 1: Time-temperature curves (left)

Figure 2: Residual compressive strength (right)

\subsection{Effect of test conditions during heating}

To determine the influence of the test conditions at the residual strength, TC and SCC $150 \mathrm{~mm}$ cubes were heated up to $350^{\circ} \mathrm{C}$ and $550^{\circ} \mathrm{C}$. This time, the cubes were not preheated. Under standard test conditions the cubes were heated at a rate of $3.5^{\circ} \mathrm{C} / \mathrm{min}$, kept at the target temperature for 750 minutes and then cooled down in ambient air (Figure 2). One of these conditions is altered while the other remain the same as the standard. The heating rate is changed to $10^{\circ} \mathrm{C} / \mathrm{min}$ for $\mathrm{TC}$ and $20^{\circ} \mathrm{C} / \mathrm{min}$ for $\mathrm{SCC}$. The duration at the target temperature was 3600 minutes and the cooling regime was modified into a rapid cooling by immersion under water.

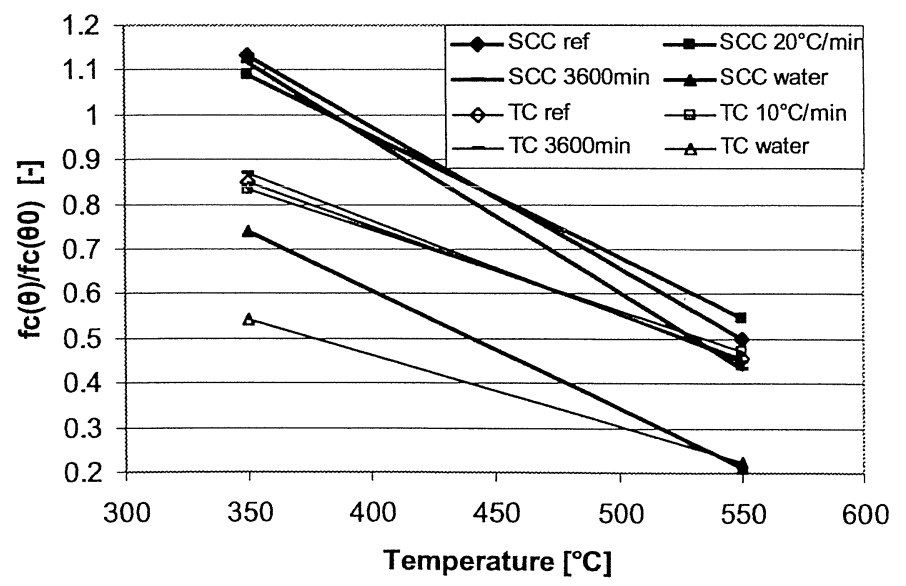

Figure 3: Influence of different test conditions on the residual compressive strength 
Figure 3 shows the effect of the different testing regimes on the residual strength (measured immediately after cooling). It seems that the cooling method is the most important parameter, resulting in an extra drop of the residual strength of 30-35\%. Notice that the SCC cubes have a $110 \%$ strength increase at $350^{\circ} \mathrm{C}$, while in Figure 2 the strength then already decreases.

\subsection{Effect of storage conditions after heating}

One hundred fifty millimetre cubes were heated at $350^{\circ} \mathrm{C}$ and $550^{\circ} \mathrm{C}$, after which they were stored under water or in air for 7, 28 and 56 days. The test parameters are the same as the standard conditions mentioned before. Figure $4 \mathrm{a}$ illustrates that the strength decreases to a minimum around 7 days after heating and that it recovers from then on. The strength recovery is faster for the cubes stored under water. Apart from ' $\mathrm{TC} 550^{\circ} \mathrm{C}$ water recured', the strength at 56 days is lower than the strength immediately after cooling as showed in Figure 2. Therefore, these results should be considered when evaluating the residual strength of a concrete member. Figure $4 \mathrm{~b}$ shows the compressive strength decrease for $150 \times 300 \mathrm{~mm}$ cylinders immediately after heating and after a storage period of 12 weeks in ambient air. Again, an additional strength decrease of 20 to $30 \%$ is noticeable.
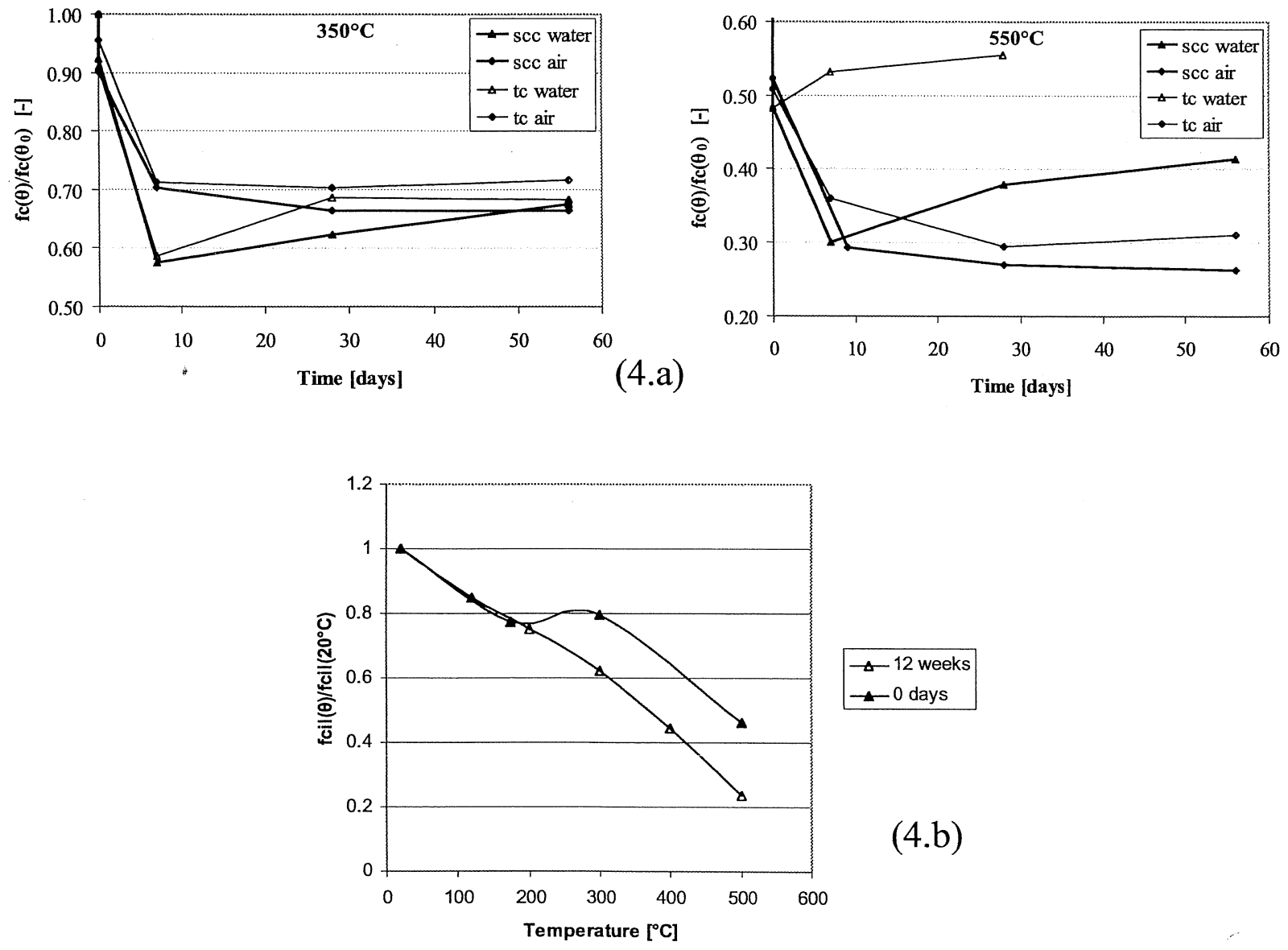

Figure 4: Further strength decrease and recovery of cubes (4.a) and cylinders (4.b) during storage after heating 


\section{ASSESSMENT OF THE TEMPERATURE PROFILE}

\subsection{Colorimetry}

After a 2 months curing period at $60 \% \mathrm{RH}$ and $20 \pm 1{ }^{\circ} \mathrm{C}$, two cores were drilled out of one 150 $\mathrm{mm}$ cube SCC and TC, which were sawn in 6 discs, polished and dried till testing time for at least two weeks at $60^{\circ} \mathrm{C}$. Since this was repeated for another cube casted at a later time, in total 24 discs were obtained for each type of concrete. Two discs (belonging to different mixes) were heated without mechanical load at a heating rate of $30^{\circ} \mathrm{C} / \mathrm{min}$ to the target temperature (till $1160^{\circ} \mathrm{C}$ ), which was kept constant for $1 \mathrm{~h}$. The discs were slowly cooled down in the oven, after which they were immediately tested for colour and porosity or were stored at $60^{\circ} \mathrm{C}$ till testing.
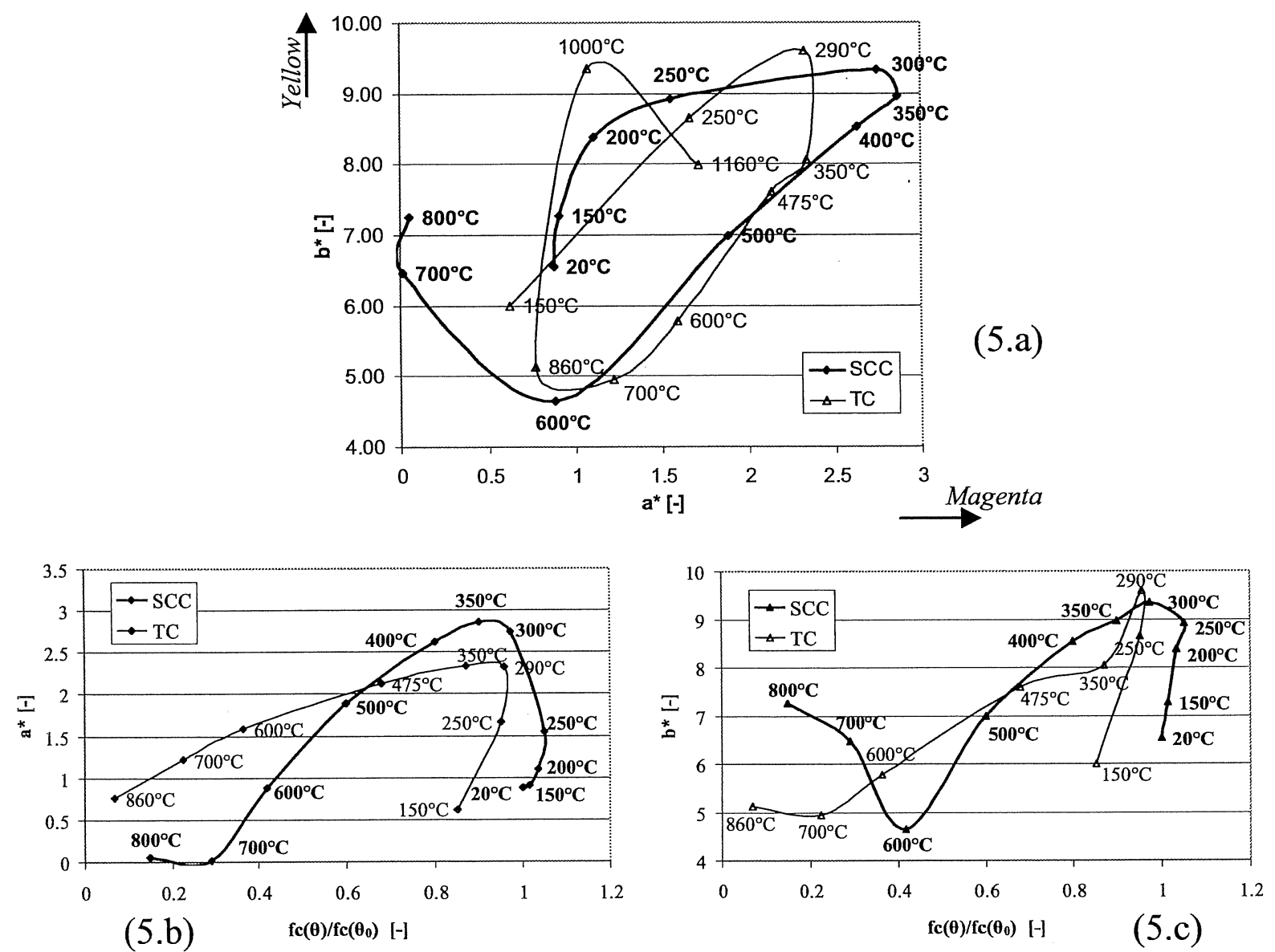

Figure 5: (L)ab-measurements and relation to the compressive strength reduction

The colour is measured with an X-rite SP60 spectrophotometer according to the CIE Labcolour space. In this colour system ' $\mathrm{L}$ ' is the lightness with values between 0 (black) and 100 (white), while ' $a$ ' is spread between magenta (positive values) and green (negative values) and ' $b$ ' is positioned between yellow (positive values) and blue (negative values). The coarse aggregates were masked with black ink to minimize the effect of the colourful aggregates. During heating the colour describes an elliptical path in the $\mathrm{a}^{*} \mathrm{~b}^{*}$-colour space (Figure 5a). In relation to the compressive strength, a peak is noticeable around $300^{\circ} \mathrm{C}$ corresponding to the 
development of a red tint (Figure 5b) and of a yellow tint (Figure 5c). The curves are similar for SCC and TC, except for the yellow tint at $800^{\circ} \mathrm{C}$. The development of a buff tint can be seen in Figure $5 \mathrm{a}$ for TC at temperatures of $1000^{\circ} \mathrm{C}$ and $1160^{\circ} \mathrm{C}$. The difference in the elliptical path between SCC and TC can be attributed to the change in concrete composition as well as the fixed aperture of $8 \mathrm{~mm}$ of the spectrophotometer. Since SCC has less coarse aggregates but more cement matrix than TC, the colour will be measured over a smaller number of masked aggregates and a larger amount of cement matrix. This results in the observed difference, because for SCC the colour will be averaged over a greater amount of colourful sand particles in the cement matrix, which are not masked, and less black from the masked aggregates.

For in situ expertise methods it is interesting to measure the colour of the fire exposed concrete directly on the concretes surface, without needing to drill cores. Therefore, TC and TCk cubes are cut in two halves and heated to different temperatures according to the standard test conditions mentioned before. For each temperature level one half cube is stored under water $\left(20 \pm 1^{\circ} \mathrm{C}\right)$ and the other half in air (RH $\left.60 \% ; 20 \pm 1^{\circ} \mathrm{C}\right)$. The colour of the surfaces of the in air stored cubes (Figure 6) and also the colour change of the calcareous aggregates of TCk (Figure 7) are recorded during a testing period of 90 days. Again, the elliptical path is clearly visible for the TC concrete surface and this alters a little bit for TCk. Notice that these concrete surfaces don't have colourful aggregates and that they are not polished. When concrete ages a shift of the colours can be seen towards the inner part of the elliptical path. This can probably be attributed to the moisture absorption, because a linear relationship between the colour change $(L, a, b)$ and the weight increase can be found with a $R^{2}$ of $0.7-0.8$. Because of this linear relationship, the angle drawn from the colour at $20^{\circ} \mathrm{C}$ to the colour changes at higher temperatures stays more or less the same and so could be used to determine the temperature regions. The moisture absorption as method to assess the temperature of the cubes stored under water will be discussed in section 3.4 .
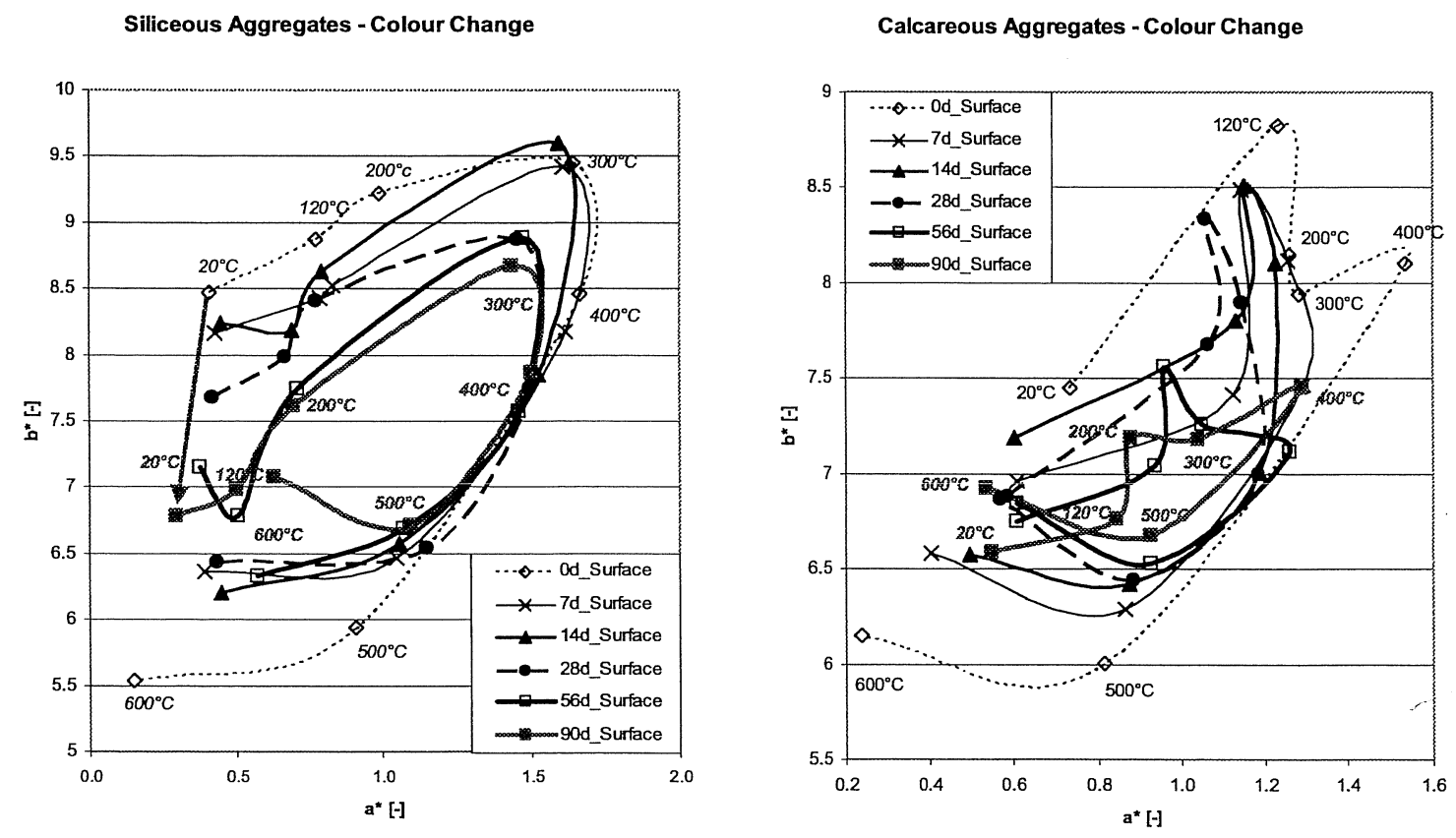

Figure 6: Colour development at concrete surface as function of moisture absorption in time 


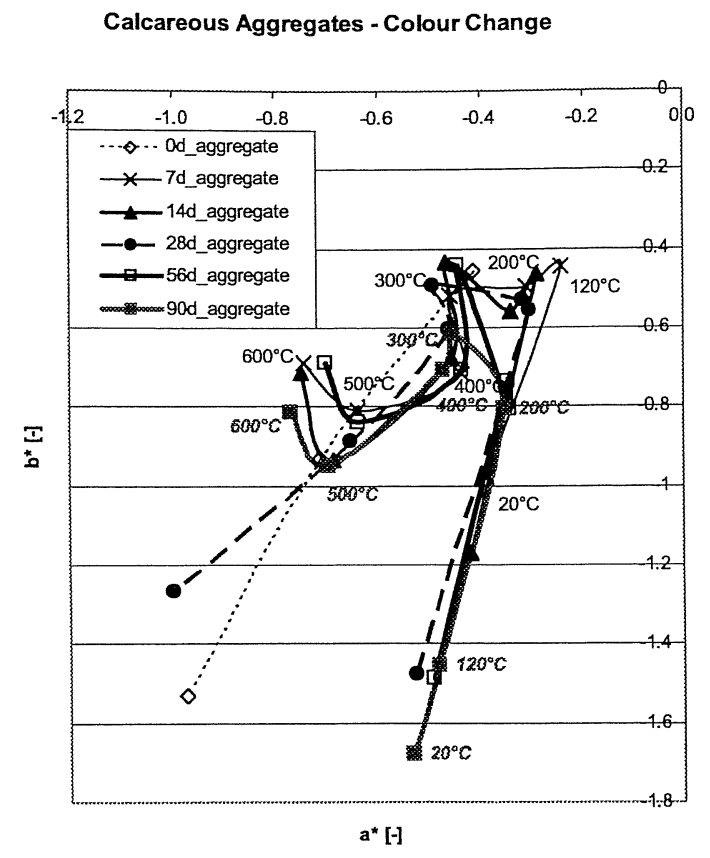

Figure 7: Colour development of calcareous aggregate as function of moisture absorption in time

\subsection{Crack development}

For the macroscopic determination of the porosity, the surfaces were completely blackened and the pores and cracks were filled with white $\mathrm{BaSO}_{4}$ powder, according to the method used for the automatic analysis of the air void structure of concrete (RapidAir 457). A picture was obtained by a flatbed scanner, from which the total porosity and the size distribution was analysed with the standard image processing programme ImageTool. Since this was done at $600 \mathrm{dpi}$, the smallest pore diameter that could be measured is 50 micrometre. No spalling occurred due to the drying period of two weeks at $60^{\circ} \mathrm{C}$.

Figure 8a presents the total porosity in relation to the heating temperature and is determined as the ratio of the total area of white pixels to the total sample surface. A curve can be fitted to the measured points, which shows a constant value until a transition temperature from where it increases almost linear. This type of curve is also found in [2] for Thames Valley aggregate concrete. The transition temperature differs for TC and SCC to respectively $200^{\circ} \mathrm{C}$ and $400^{\circ} \mathrm{C}$. The fewer coarse aggregates in SCC, resulting in a lower contact surface between the aggregates and the cement matrix (interfacial zone) and therefore leading to less differences in thermal expansion and so less cracks in this zone, could explain this. The difference in interfacial crack width between SCC and TC is clearly visible on the polished specimens. The slope of the increasing part of the curves apparently depends on the testing conditions (size of samples, heating rate, heating duration, method of cooling) but is almost the same for the SCC and TC tested in this research project. 

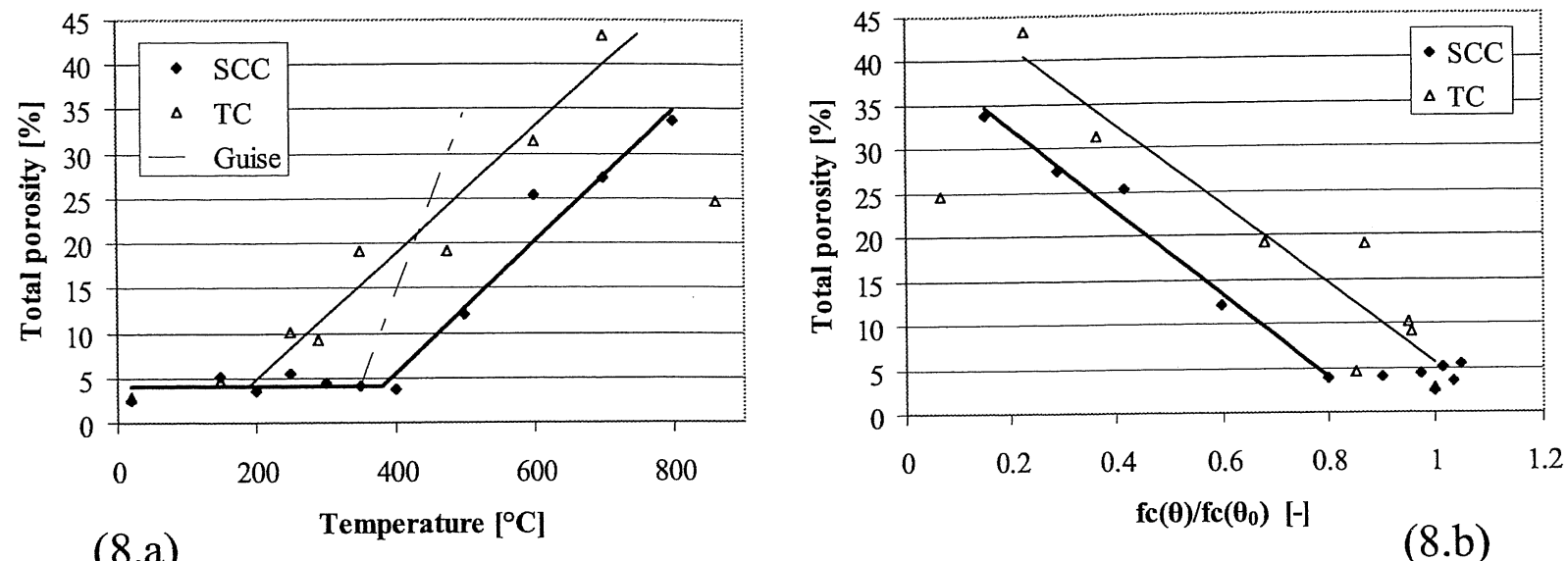

(8.b)

Figure 8: Relationships between the temperature, the total porosity and the strength decrease

Figure $8 \mathrm{~b}$ shows the direct relation between the total porosity and the strength loss. Until the transition temperature no difference in porosity can be measured although there is a certain degree of strength degradation. Other methods as SEM and MIP do show a variation in porosity [7], because they analyse pores with a smaller diameter than 50 micrometre, which is the minimum class detected with the flatbed scanner. [2] and [3] mention that the transition temperature can be easily determined from drilled cores and that this point can be considered as the onset of strength degradation. It would be useful if also the temperature levels above the transition temperature could be linked in absolute terms to a change in porosity. This way a temperature profile could be assessed based on the crack pattern of drilled cores. However, the amount of cracks is influenced by the heating and cooling conditions as well as the storage conditions after fire, but considering the results of section 2.2, this could probably be minimised, except for water cooling.

When temperature increases, cracks arise around the aggregates due to the difference in thermal expansion between the aggregates and the cement matrix (Figure 9). Therefore, interfacial cracks develop around the coarse aggregates, while cement matrix cracks start around the sand particles and connect at higher temperatures. The crack width development is measured and related to the residual strength in Figure 10.

From Figure 11a, it can be seen that the increase in porosity is spread over all measuring classes. The peak around 1000 micrometre can be attributed to the interfacial cracks. From this size distribution the influence on porosity of the interfacial cracks and the cement matrix cracks can be determined (Figure 11b). It appears that they increase both at the same rate.

The change in porosity has also been studied under recuring conditions. The first results of this test program show again a good relationship between the change in strength and porosity. However, the amount of porosity corresponding to a given strength reduction seems not to be the same as in Figure 8a, due to the differences in the test and storage conditions. Therefore, the influence of these parameters should be further studied to calibrate the slope of the curve. 

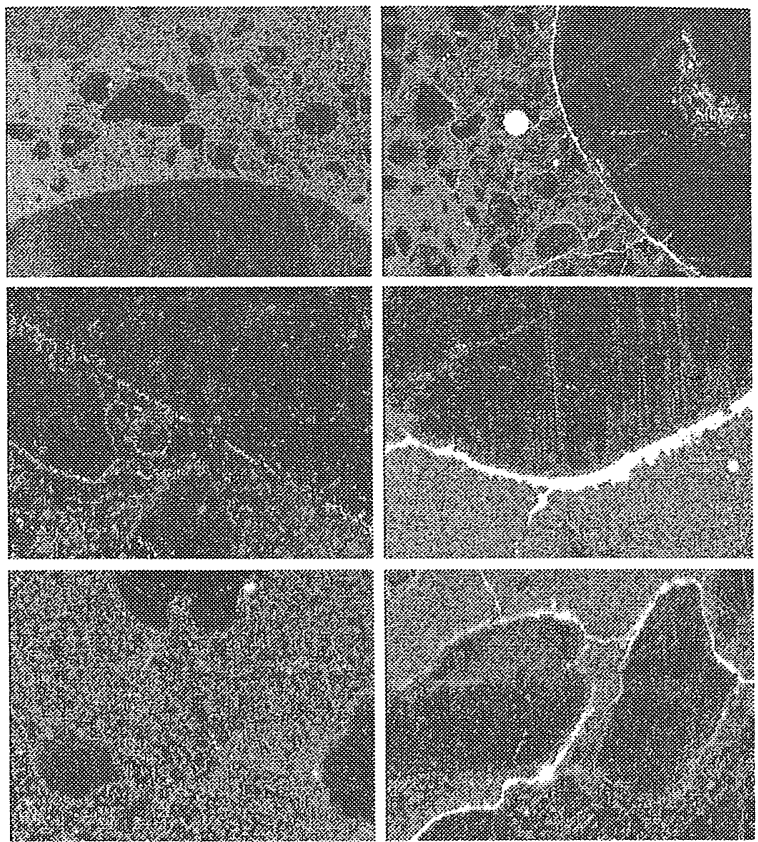
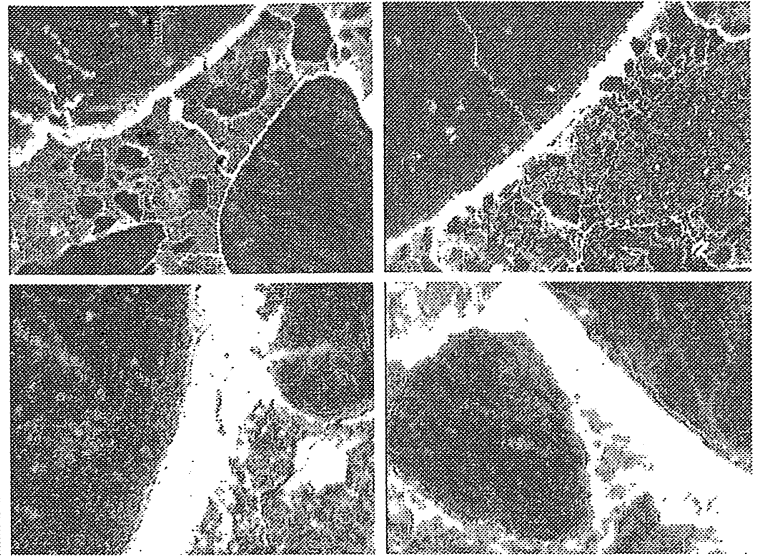

$35 x$
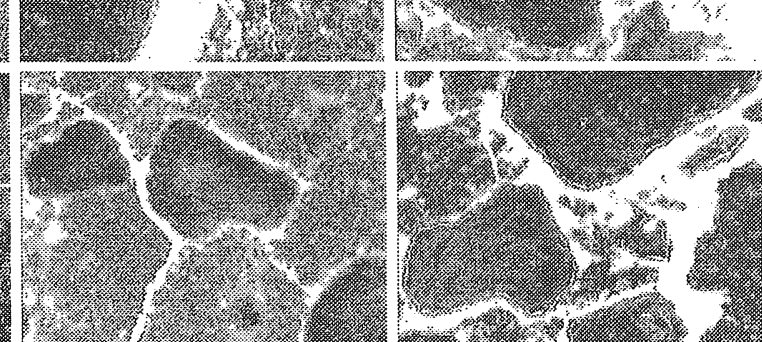

210x

210x

Figure 9: Crack development at $20^{\circ} \mathrm{C}$ (left), $400^{\circ} \mathrm{C}, 600^{\circ} \mathrm{C}, 800^{\circ} \mathrm{C}$ (right) in the interfacial zone (top: magnification x35; middle: $\mathrm{x} 210$ ) and the cement matrix (lower: $\mathrm{x} 210$ ).
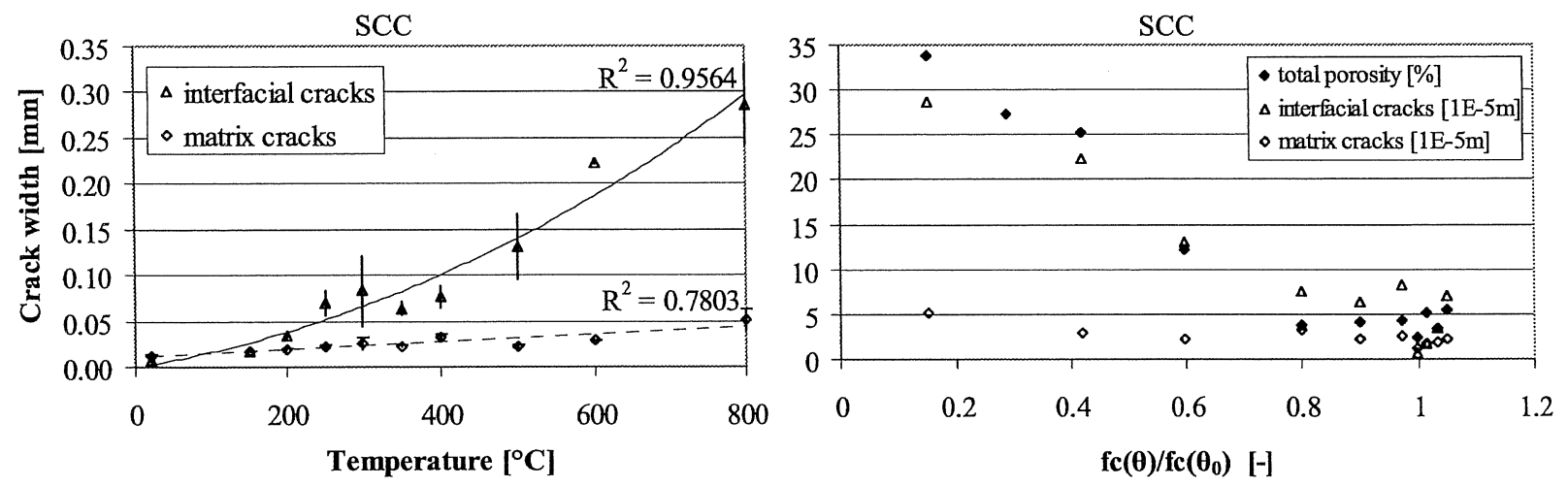

Figure 10: Relationships between crack width, temperature and residual strength
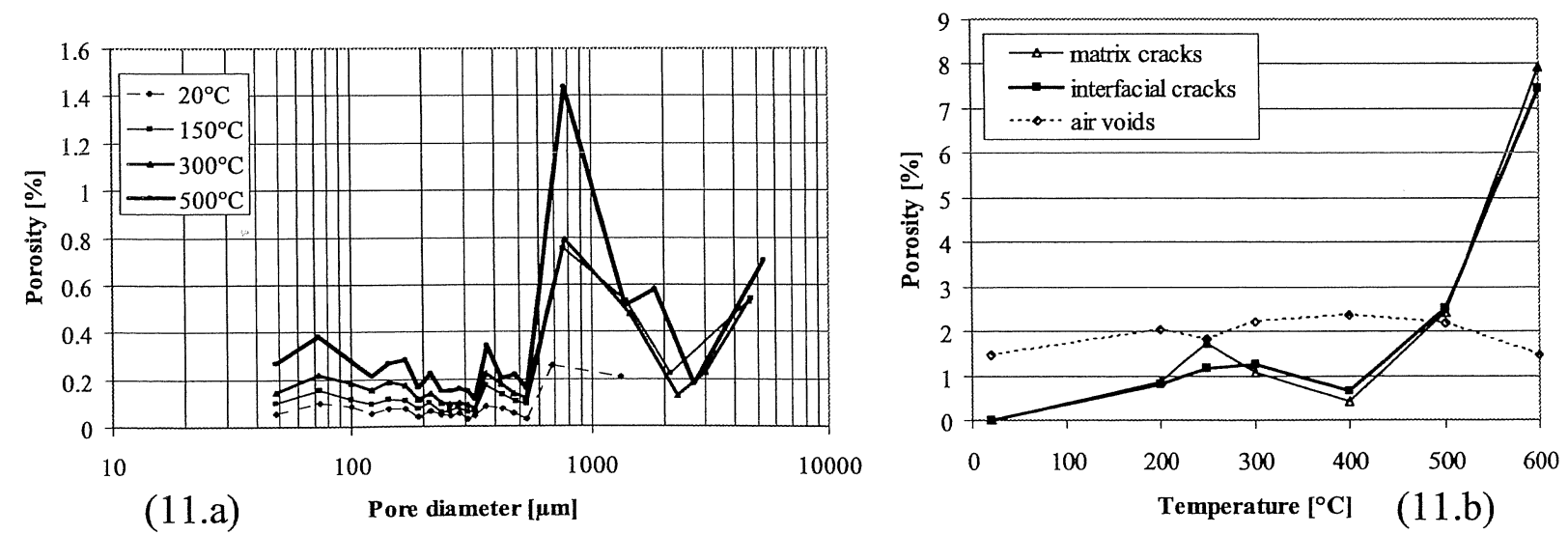

Figure 11: Size distribution (left) and the influence on porosity of the cracks (right) 


\subsection{Schmidt Rebound Hammer Index}

The surface hardness of the half cubes described in section 3.1 (Figures 6 and 7) is determined with the Schmidt Rebound Hammer for up to 90 days and is visible in Figure 12. It seems that the results at 0 days after heating are more or less in the neighbourhood of the Eurocode [1]. However, the degradation around 7 to 28 days, as noticed in Figure 4, is not always apparent on the graph. Differences in the strength recovery between storage under water and in air are clearly visible, while it seems that the recovery is greater for TCk than for TC. Due to atmospheric effects such as rain and sun, measurements on in-situ structures will be between the extremes as presented on the graphs.

Calcareous Aggregates

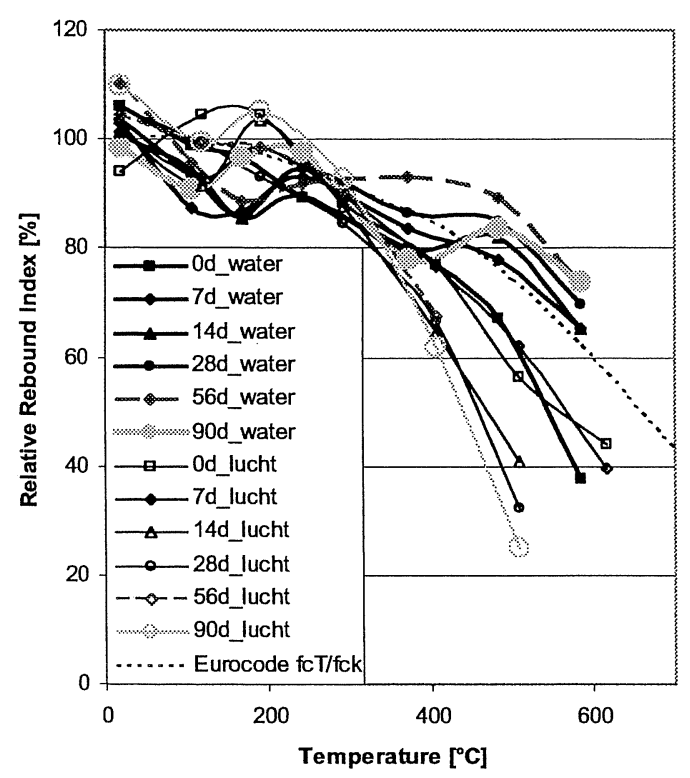

Siliceous Aggregates

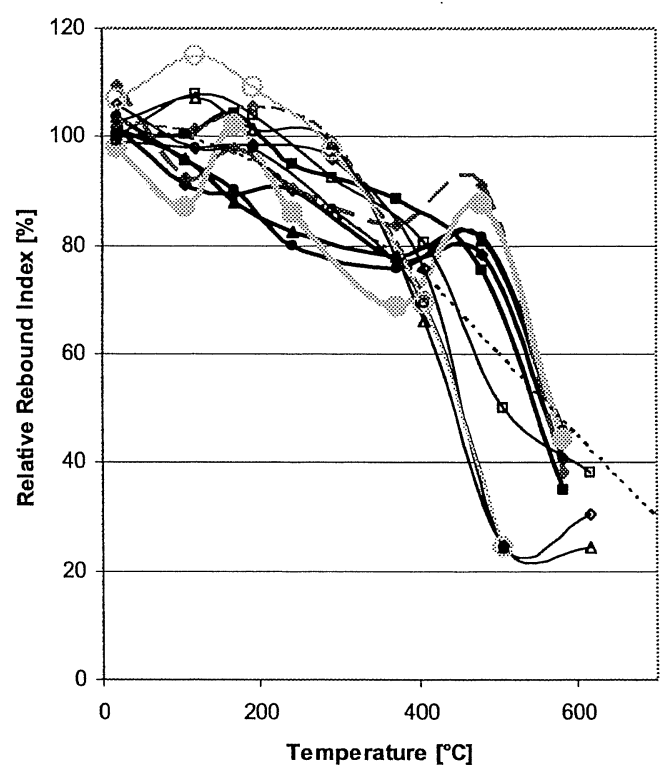

Figure 12: Relative Schmidt Rebound Hammer Index

\subsection{Water immersion}

Figure 13 demonstrates the weight increase due to a 7 days immersion (increasing lines) of the half cubes (see section 3.1), and the water loss due to heating measured immediately after cooling (dropping lines). It seems that the weight change is the highest for TCk and this can be seen as a measure of porosity since it shows a linear relationship ( $\mathrm{R}^{2}$ of 0.98 for $\theta \geq 200^{\circ} \mathrm{C}$ ) with the porosity determined on the polished samples as illustrated in Figure 8 . The method of water immersion is very promising, because the reference weight is the investigated (heated) sample, preferably after drying. In contrast, the method of the weight loss requires a non heated reference sample, while the building was heated and so the uncertainty of a non heated sample or differences in the concrete composition and so the initial porosity are then important. This storage under water of samples from a drilled core could be a quick and cheap alternative to the method of polished samples. The weight increase due to storage in air can also be used, but has lower differences in value. 


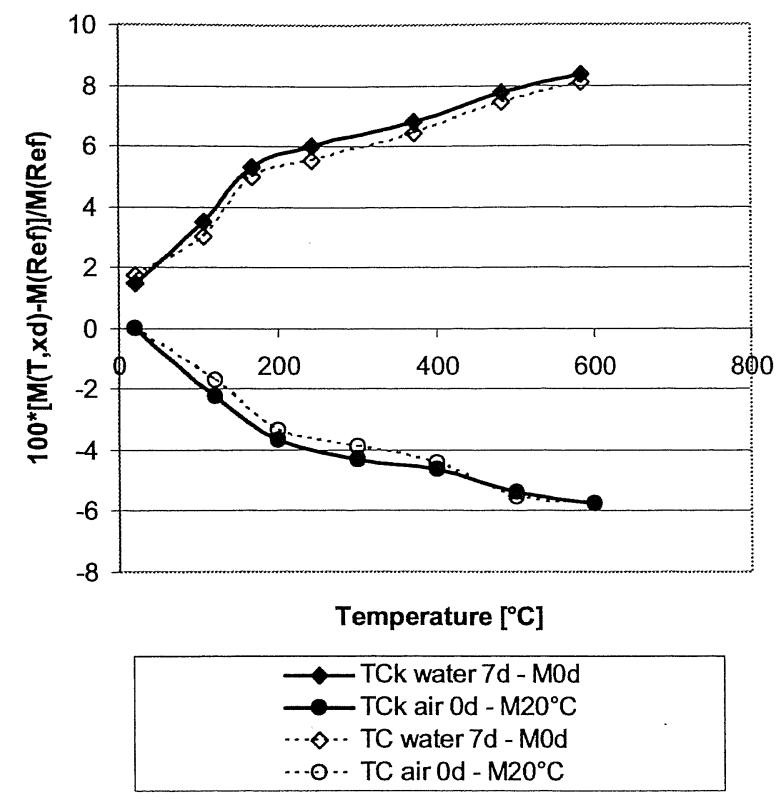

Figure 13: Weight loss after heating (dropping lines) and weight increase during water immersion (increasing lines)

\subsection{Microscopy}

The microscopy can also help to determine the fire damage caused at a concrete structure. According to [8] several degradation periods can be seen under the polarising and fluorescent microscope. Not only the change in fluorescence intensity above $100^{\circ} \mathrm{C}$, the dissociation of ettringite $\left(>70^{\circ} \mathrm{C}\right)$, but also the oxidation of the iron in the siliceous aggregates at $350^{\circ} \mathrm{C}$ and the disappearance of the portlandite in the temperature region $450^{\circ} \mathrm{C}$ to $500^{\circ} \mathrm{C}$ can be clearly noticed. However, under the electron microcope this dissociation process can be seen more in detail (Figure 14). These images are taken at the interfacial transition zone of traditional, Portland cement based concrete. At $20^{\circ} \mathrm{C}$ the bonding between the cement matrix and the aggregate is good and shows a lot of portlandite, $\mathrm{CSH}$ and ettringite. At $350^{\circ} \mathrm{C}$ the ettringite is dissociated and a interfacial crack is visible, while at $550^{\circ} \mathrm{C}$ even the portlandite is depleted in the cement matrix resulting in a more porous matrix.
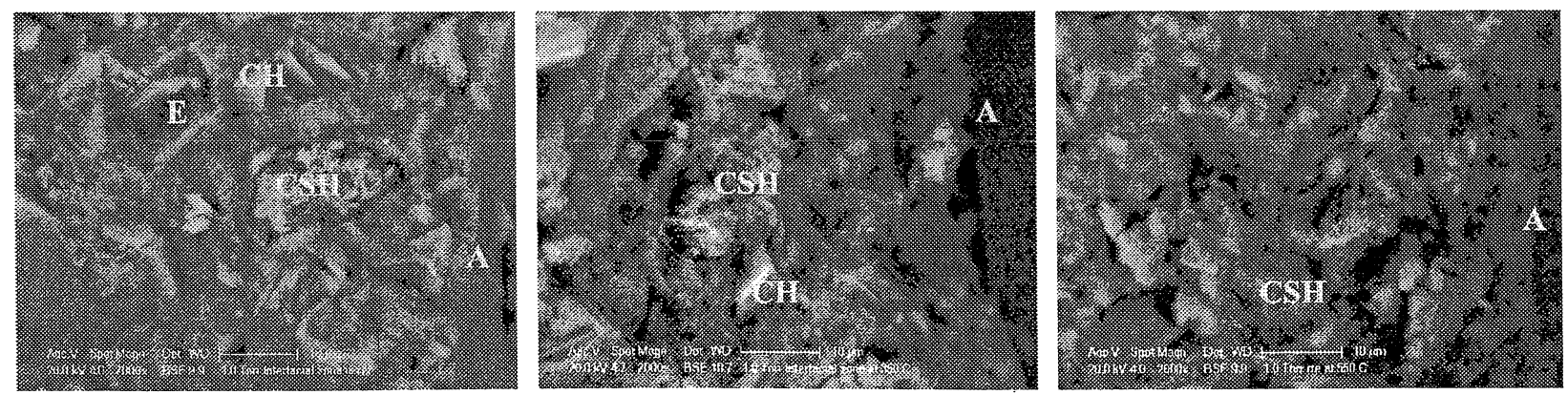

Figure 14: ESEM images of traditional, Portland cement based concrete at $20^{\circ} \mathrm{C}$ (left) and heated up to $350^{\circ} \mathrm{C}$ (middle) and $550^{\circ} \mathrm{C}$ (right). $\mathrm{E}=$ ettringite, $\mathrm{CH}=$ portlandite and $\mathrm{A}=$ aggregate. 


\section{CONCLUSIONS}

- $\quad$ The residual strength should be measured at least 7 days after the end of the fire or the heating period. Water cooling may induce an additional reduction of the compressive strength of 30 to $35 \%$.

- When concrete has been heated, the colour change of the matrix follows an elliptical path in the $a^{*} b^{*}$-colour space and shifts to the inner part as a function of moisture absorption.

- A distinction should be made between matrix cracks and interfacial cracks; the total porosity seems to be a good indicator to estimate the maximum temperature which was reached in the heated concrete.

- $\quad$ Other methods such as the Rebound Index, water absorption, PFM and ESEM yield also useful results.

\section{ACKNOWLEDGEMENTS}

The authors would like to thank the Fund for Scientific Research in Flanders (FWO) for the financial support; and are thankful for the help of TNO Delft and TU Delft (Netherlands) for their contribution to the microscopic research.

\section{REFERENCES}

[1] EN 1992-1-2: 2004 - Eurocode 2: Design of Concrete Structures - Part 1-2: General Rules - Structural Fire Design, CEN, Brussels, 2004, 97 pp.

[2] Guise S.E. - The Use of Colour Image Analysis for Assessment of Fire Damaged Concrete, $\mathrm{PhD}$ thesis, The University of Aston, 1997, $192 \mathrm{pp}$.

[3] Felicetti R. - "Digital Camera Colorimetry for the Assessment of Fire-Damaged Concrete", Fire Design of Concrete Structures: What now? What next, Proceedings of the Workshop, fib Task Group 4.3 'Fire Design of Concrete Structures', Milan, 2004, pp.211220.

[4] Mohamedbhai G.T.G. - "Effect of exposure time and rates of heating and cooling on residual strength of heated concrete", Magazine of Concrete Research, vol. 38, no. 136, 1986, pp. 151-158.

[5] Sarshar R. \& Khoury G.A. - "Material and environmental factors influencing the compressive strength of unsealed cement paste and concrete at high temperatures", Magazine of Concrete Research, vol. 45, no. 162, 1993, pp. 51-61.

[6] Poon C.S. - "Strength and Durability Recovery of Fire-Damaged Concrete after Post-FireCuring", Cement and Concrete Research, vol. 31, no. 9, 2001, pp. 1307-1318.

[7] Liu X., - Microstructural Investigation of Self-Compacting Concrete and HighPerformance Concrete during Hydration and after Exposure to High Temperatures, $\mathrm{PhD}$ thesis, Ghent University, 2006, 174 pp.

[8] Larbi J.A., Nijland T.G. - "Unravelling the temperature distribution in fire-damaged concrete by means of PFM microscopy: Outline of the approach and review of potentially useful reactions", HERON, vol. 46, no. 4, 2001, pp. 253-264. 